\title{
QUESTÕES DE GÉNERO EM ARQUITETURA: HISTÓRIA(S), ESPAÇO(S) E EXPERIÊNCIAS PROFISSIONAIS E ARQUITETÓNICAS
}

Lia Pereira Saraiva Gil Antunes

Empresa Formas Efémeras, Portugal

\section{Resumo}

Por diversas razões, que também dependem do contexto histórico e social em que ocorrem, em muitas situações as mulheres têm sido excluídas da história ou apresentam papéis secundários. A arquitetura tem apoiado o seu reconhecimento na vida dos grandes mestres e nas suas obras, como «faróis históricos» capazes de legitimar a quase totalidade de um discurso disciplinar. Posto isto, e uma vez desvendado este cenário masculinizado, inclui-se tanto uma breve história das arquitetas (a nível mundial) bem como o fenómeno da feminização do curso superior em questão. Relativamente à profissão, expõem-se quais as especificidades atuais desta, sobretudo em Portugal, tendo em conta o desemprego, a conciliação das esferas profissional-pessoal-familiar-social, o conceito de "carreira», as expectativas e a gestão do tempo no binómio trabalho-ócio, usando a revisão bibliográfica como metodologia de investigação.

Palavras-chave: Arquitetura, género, profissão, mulheres.

\begin{abstract}
Gender issues in architecture: history(s), space(s) and professional and architectural experiences

For many reasons, which also depend on the historical and social context in which they occur, in many occasions women have been excluded from the history or they have secondary roles. The architecture has supported its recognition in the life of the 'great masters' and their works, as 'historic lighthouses' able to legitimize almost all of a disciplinary discourse. So, once unraveled this male scenario, it includes both a brief history of architects (worldwide) and the phenomenon of the feminization of higher education in this subject. Concerning the profession, it is exposed which the current features of this, especially in Portugal, taking into account the unemployment, the conciliation of the work-family-personal-social levels, the concept of "career», the expectations and the management of time in the work-leisure binomial, using literature review as research methodology.
\end{abstract}

Keywords: Architecture, gender, profession, women.

\section{Resumen}

Cuestiones de género en la arquitectura: historia(s), espacio(s) y experiencias profesionales y arquitectónicas

Por variadas razones, que también dependen del contexto histórico y social en que se producen, en muchas situaciones las mujeres han sido excluidas de la historia o fueron relegadas a un segundo plano. La arquitectura ha apoyado su reconocimiento en la vida de los grandes maestros e en sus obras, como «faros históricos» capaces de legitimar la casi totalidad del discurso arquitectónico. Así, y una vez desenredado este escenario masculino, se incluye tanto una breve historia de las arquitectas (a nivel mundial) así como el 
fenómeno de la feminización de la educación superior. Con respecto a la profesión, se exponen cuáles son las especificidades de esta, sobretodo en Portugal, teniendo en cuenta el desempleo, la conciliación de los niveles profesional-personal-familiar-social, el concepto de «carrera profesional», las expectativas y la gestión del tiempo en el binomio trabajo-ocio, utilizando la revisión bibliográfica como metodología de la investigación.

Palabras-clave: Arquitectura, género, profesión, mujeres.

\section{Introdução}

Atualmente as mulheres estão a exercer pressão na profissão de arquiteta tal como outros grupos [de poder] minoritários, particularmente o movimento Black power, fizeram na década de 1960. A arquitetura nunca mais será a mesma ${ }^{1}$ (Brown, 2010: 113).

No discurso contemporâneo baseado na heterogeneidade de continuidades e ruturas, a arquitetura tem de se reposicionar permanentemente, sincronizandose com o contexto envolvente e as circunstâncias do presente. $\mathrm{O}$ arquiteto idealizado por Vitrúvio deveria possuir um conhecimento geral quase enciclopédico, aproximando-se do que seria o artista perfeito. Atualmente, não se concebe o/a arquiteto/a como detentor/a do conhecimento universal, pede-se-lhe sim que trabalhe em equipa e com outras disciplinas; a entrada e colaboração de outros saberes com a arquitetura têm posto em causa dogmas antigos e velhas ideias e preparam uma nova vida para a disciplina. Neste contexto, a valência de género tem vindo a derrubar algumas noções convencionais, incutindo-lhes uma nova vitalidade - diferente da sucessiva construção androcêntrica.

Segundo Elena Salvatori, «A feminização do campo profissional [da arquitetura], porém, é um fenómeno que se vem configurando incisivamente ao longo do tempo, sob o influxo das transformações sociais e económicas ocorridas na segunda metade do século XX» (2008 apud Sá, 2010: 19). Kazuyo Sejima, que estudou na Universidade de Mulheres do Japão, numa entrevista ao jornal El País (Zabalbeascoa, 2008), refere que o problema está na forma como se procura fazer e pensar a "grande arquitetura», a mais visível, pois está demasiado politizada no sentido do mundo tipicamente masculino. É fundamental perceber quais as contribuições das mulheres para a arquitetura e que mudanças podem trazer ou efetivamente trouxeram à disciplina. Para tal, é preciso conhecer em que situações e em que moldes é que elas arquitetam, de forma a impulsionar um processo que permita incorporar a visão transversal do género na organização da profissão.

No original: «Women today are exerting pressure on the architecture profession just as other entering groups, particularly the Black power movement, did in the nineteen-sixties. Architecture will never be the same again». 
Tais reflexões são feitas com base na revisão bibliográfica, sem recorrer à recolha e tratamento de dados empíricos. O presente artigo estrutura-se fundamentalmente em dois eixos: primeiro, aborda-se a história sucinta de uma profissão de homens (na qual têm lugar conceitos como star system, heróis, autoria e génio), e em segundo, a (outra) história das mulheres na arquitetura (quem foram as pioneiras, qual a situação educacional e profissional em Portugal, os prémios de relevo e experiências profissionais de arquitetas).

\section{Uma profissão (que era) de homens}

O status quo do arquiteto desenvolveu-se dentro do contexto renascentista no qual a arquitetura era um serviço do artista/artesão para o poderoso mecenas, não existindo lugar para as mulheres. A exaltação do «arquiteto-artista-herói» desde as fundações da arquitetura ocidental prevalece na história, por exemplo, através do Manifesto Futurista, escrito em 1908 pelo escritor italiano Filippo Marinetti e publicado em 1909 no jornal Le Fígaro. Este manifesto marca o início do advento da vanguarda progressista no virar do século $X X$, prometendo um papel positivo para a arquitetura no que diz respeito à trajetória Iluminista da razão e do génio, que serve de símbolo para a propagação dos ideais de uma civilização universal e, portanto, masculina, como se verá posteriormente. Antonio Sant' Elia e Mario Chiatonne, arquitetos que seguiram as proclamações futuristas para uma cidade nova, usam conceitos que glorificam a guerra, o militarismo e a violência, exaltam a obra-prima de carácter agressivo e o desprezo pela mulher e pelo feminismo:

Marinetti declara sua a oposição à ênfase da psicologia sobre emoções e paixões humanas em favor de uma obsessão lírica com a matéria (...) Em resumo, a humanidade é um objeto a ser estudado e escrutinado e não dramatizado e sentimentalizado. Ele refere-se à nova criação, o «novo homem», em termos que sugerem uma fusão violenta e animalesca entre máquina e corpo humano. (...) A conceção do futurismo de Marinetti requer estigmatizar e difamar o corpo feminino para alcançar a sua anunciada visão do futuro (...) noção de «família» é, claro, centrada no corpo das mulheres, a sua capacidade de se reproduzir, e os seus papéis sociais como mães e esposas² (Heumann, 1998: s/p).

No original: «Marinetti declares his opposition to psychology's emphasis upon human emotions and passions in favor of a lyric obsession with matter (...) Humanity, in short, is an object to be studied and scrutinized, not dramatized and sentimentalized. He refers to the new creation, the 'new man', in terms that suggest a violent, animalistic merging of machine and human body. (...) Marinetti's conception of Futurism requires that he both stigmatize and vilify that female body to achieve his prescribed vision of the future (...) notion of «family» is, of course, centered on women's bodies, their ability to reproduce, and their social roles as mothers and wives». 
Os futuristas proclamam o dinamismo plástico e as formas oblíquas para o início do século, por entre um discurso sexista, misógino e repressor, que pretende uma arquitetura que concilie livre e ousadamente o homem (e apenas o homem) e o seu ambiente. Posteriormente, os aclamados mestres modernos deixaram a impressão de que após eles nada de diferente podia ser pensado ou dito.

As ideologias que estão subjacentes a toda a produção humana estão em perpétua evolução; todavia, Alexander Tzonis nota que o principal impedimento a alterações no quadro concetual e profissional da arquitetura é que:

(...) o status quo da profissão opõe-se à mudança e tenta manter as posições adquiridas. Tal disparidade reside mais na oposição dos membros de uma sociedade (desenhistas incluídos) às autoridades desta mesma sociedade, à sua estrutura, à distribuição do poder entre os seus membros; à maneira pela qual exprimem a sua tomada de consciência da opressão do que na diferença que existe realmente entre os seus conceitos de ambiente e de design (Tzonis, 1976: 649).

Assim, a crise da arquitetura está relacionada com o pedestal em que o arquiteto se coloca e com a incapacidade do homem em criar um ambiente nãoopressivo; contudo, o autor não formula a hipótese da participação e do reconhecimento das contribuições das arquitetas poder (ou não) alterar este cenário. Elas podem ser agentes ativos de uma nova visão do ambiente não-opressivo o que, ainda assim, não implica que os conceitos e categorias pelas quais se rege a arquitetura sejam históricos e façam parte da evolução da organização do poder na sociedade. Todavia, este fato não implica que a arquitetura se transforme e faça uma autocrítica, capaz de alterar os paradigmas socioculturais dentro da disciplina, começando por (re)escrever uma história dissociada do domínio masculino.

Por outro lado, a história da arquitetura prova a constante relação, simbólica e metafórica, do corpo da mulher com a forma e a imagética da arquitetura. É legítimo que as mulheres possam mostrar algum receio em integrar um universo disciplinar que, simbolicamente, é liderado pelo homem e que foi formulado tantas vezes por reações conservadoras e preconceituosas quanto às questões de género, por parte de clientes, construtores, e mesmo de colegas.

a) Condicionantes à reformulação da disciplina em relação à integração do papel das mulheres

O tema do star system (conceito referente à glorificação da disciplina tendo por base arquitetos-estrela) está presente nos textos standard do século XX mas de forma bastante explícita na obra de Andrew Saint, The Image of the Architect (1983). Saint traça a história da arquitetura enquanto profissão, do século XVIII até ao século XX, de acordo com o seu status na sociedade e com a imagem pública que produz. O autor explora a suas diversas personalidades - o herói, o 
génio, o profissional, o homem de negócios e o "cavalheiro». Por um lado, a masculinidade do arquiteto não se apresenta meramente como facto histórico mas como algo que permanece por examinar e a participação das arquitetas mantêmse ausente. Por outro, a arquitetura tecnológica das corporações ocidentais representa em grande medida o sistema capitalista e macho male que serve como metáfora para o sistema industrial das cidades. Para Linda Nochlin, o facto de as mulheres terem um papel menos visível no campo das artes prende-se, entre outros problemas, com esta ofuscação intelectual sob a rubrica do «génio» que

(...) é pensado como um poder atemporal e misterioso, de alguma forma incorporado na pessoa do Grande Artista. (...) Subjacente à pergunta sobre a mulher como artista, encontramos, então, o mito do Grande Artista - assunto de centenas de monografias, único, divino - carregando na sua pessoa desde o seu nascimento uma misteriosa essência $(. . .)^{3}$ (Nochlin, 1994: 153).

A combinação da proposição intelectual com a atenção crítica altera a arquitetura, determina quem é merecedor de celebração, inadvertida ou deliberadamente e, por conseguinte, influencia a história da arquitetura:

O star system, que vê a empresa como uma pirâmide com o designer no topo, tem pouco a ver com as relações complexas de hoje na arquitetura e construção. Mas, como o sexismo me define como uma escriba, datilógrafa e fotógrafa do meu marido, então o star system define os nossos colaboradores como associados de segunda ${ }^{4}$ (Brown, 1989: 240).

Em Architecture: A Woman's Profession (2010), Tanja Kullack dedica dois capítulos aos temas «autoria e génio» e $o$ "sistema starchitect», nos quais surgem reações semelhantes entre as arquitetas entrevistadas: nos países ocidentais, a questão da autoria surge sobretudo como um instrumento de marketing pois é daqui que advém a perceção de criatividade por parte do público. Há neste debate um realce constante, por parte das arquitetas, da importância do trabalho em equipa, da discussão de ideias, da comunicação com o cliente e da complexidade do programa. Clarificam também que a expetativa da autoria singular ainda se mantém e, neste sentido, Monica Ponce de Leon nota que:

No original: «(...) is thought of as an atemporal and mysterious power somehow embedded in the person of the Great Artist. (...) Underlying the question about woman as artist, then, we find the myth of the Great Artist - subject of hundred monographs, unique, godlike - bearing within his person since birth a mysterious essence (...)».

$4 \quad$ No original: «The star system, which sees the firm as a pyramid with a designer on top, has little to do with today's complex relations in architecture and construction. But as sexism defines me as a scribe, typist and photographer to my husband, so the star system defines our associates as second bananas and our staff as pencils» 
Não há autoria de um edifício. No entanto, há ainda o mito da autoria singular, que se expressa na pergunta de quem realmente tenha concebido este ou aquele edifício, quando na verdade é o resultado de muitas pessoas (...) parece que estamos a perpetuar a ideia arcaica do «mestre arquiteto $»^{5}$ (Leon, 2010: 23).

\section{História das mulheres na Arquitetura}

As problemáticas relacionadas com o género e circundantes à arquitetura são extraordinariamente complexas e sensíveis e estão, frequentemente, carregadas de emoção. Vários autores têm vindo a defender que a cidade e a arquitetura têm deslocado a mulher para a margem, como sintetiza Judy Wajcman:

Arquitetura e urbanismo orquestraram a separação entre mulheres e homens, privados e públicos, habitação e emprego remunerado, consumo e produção, reprodução e produção, subúrbio e cidade. Embora as pessoas não vivam realmente de acordo com estas dicotomias, a crença generalizada nelas influencia decisões e tem um impacto na vida das mulheres ${ }^{6}$ (Wajcman, 1994: 2001).

As mulheres têm estado desde sempre envolvidas com o desenho e forma do espaço de várias maneiras, enquanto praticantes, teóricas, consumidoras, historiadoras e objetos de representação. Na viragem para o século XX ocorre uma transformação da sociedade e a mulher tem um novo lugar - já lhe é permitida a incorporação nos setores culturais, na esfera pública - e surgem as arquitetas pioneiras, frequentemente limitadas ao trabalho associado aos parceiros conjugais, com quem partilham a mesma profissão.

Nos últimos 50 anos, o número de mulheres no mundo que estudam arquitetura aumentou visivelmente, chegando várias vezes a representar $50 \%$ do corpo de estudantes; então, o best design work (ou seja, as obras de arquitetura reconhecidas pelos mídia da especialidade e, consequentemente, pelo público em geral) deveria ser feito por homens e mulheres na mesma proporção. Todavia, depois da formação, o número de arquitetas a exercer a profissão é bastante inferior ao de arquitetos, e elas tendem a atuar frequentemente como colaboradoras e

5 No original: «There is no authorship to a building. However there's still the myth of singular authorship, which is expressed in the question of who actually designed this or that building, when in fact is the result of many people (...) we seem to hold on to the archaic idea of the 'master architect'».

6 No original: «Architecture and urban planning have orchestrated the separation between women and men, private and public, home and paid employment, consumption and production, reproduction and production, suburb and city. While people do not actually live according to these dichotomies, the widespread belief in them does influence decisions and have an impact on women's lives». 
a liderar poucos escritórios de arquitetura. Em The Architect: The Women in Contemporary Architecture (2001), Maggie Toy refere que o facto de o número de mulheres que estuda arquitetura ser inversamente proporcional ao número das que se tornam arquitetas é uma questão internacional.

Louise Blanchard tornou-se a primeira eleita como membro do American Institute of Architects em 1888, e Ehtel Mary Charles, a primeira mulher membro do Royal Institute of British Architects, em 1898. Na Inglaterra, as mulheres puderam iniciar os estudos em arquitetura na Architectural Association (Londres) em 1917, e o Massachusetts Institute of Tecnology foi a primeira escola a oferecer vagas destinadas a mulheres no curso de arquitetura, em 1867, cuja primeira diplomada foi Sophia Hayden em 1890. Na Suíça ${ }^{7}$, Flora Crawford inaugurou a participação feminina na profissão em 1923. Em França, a Escola de Belas-Artes de Paris abriu uma exceção para uma estudante de arquitetura em 1898, a americana Julia Morgan; na Península Ibérica, mais tardiamente, Matilde Ucelay a primeira diplomada em Espanha, em 1936, e Maria José Estanco foi primeira mulher portuguesa a tornar-se arquiteta, em 1942 (Maria José Marques da Silva foi a primeira arquiteta formada pela escola portuense em 1943). As arquitetas pioneiras foram quase todas confinadas à arquitetura doméstica e à decoração de interiores, quase como um prolongamento natural das tarefas femininas. Para tal contribuíram os renovados interesses pela arquitetura doméstica, no final do século XIX, e o aparecimento dos manuais de economia doméstica, nos EUA, que deram novo destaque ao ambiente doméstico e concederam novas tarefas às mulheres a ideia era conseguir uma melhor produtividade do trabalho humano (neste caso, feminino) e enfatizar a diferenciação entre o espaço público e o privado. Os anos 20 do século XX presenciaram a revolução da arquitetura moderna e um maior número de contribuições femininas. As reformas domésticas, a tecnologia moderna e o planeamento científico pretendiam libertar as mulheres da escravidão doméstica; todavia, os Salões (mostras de arquitetura e design) mostravam ainda a casa como o local de trabalho da femme moderne.

\section{a) O palco das estudantes e arquitetas: o exemplo português}

Para se compreender os obstáculos impostos às arquitetas, tanto na profissão como na educação, é necessário perceber o cenário geral e olhar para a sociedade como um todo. Ao longo da história, o homem tem dominado todas as áreas profissionais e do conhecimento e, na exclusão da mulher, esta é a forma mais universal de diferenciação entre os sexos visto que afeta metade da população mundial. 7 Para uma história mais completa das arquitetas na Suíça, ver a tese de doutoramento de Eve-
lyne Lang (1992). 
No caso português, «as mulheres ainda estão longe de atingir a paridade em arquitectura» (Cabral e Borges, 2006: 39). Em Portugal foi elaborado o Relatório Profissão: Arquitecto/a (2006), coordenado por Manuel Villaverde Cabral, resultante de um estudo promovido pela Ordem dos Arquitetos. A investigação sociológica começa por fazer um enquadramento teórico e metodológico, onde refere que a profissão abarca uma variedade de trajetórias de carreira, de modalidades de emprego e de tipos de atividades, numa tentativa de perceber como é que os arquitetos e as arquitetas constroem as suas identidades profissionais. Partindo da noção de "sociologia das profissões», os/as autores/as questionam se o universo da arquitetura corresponderá ao que, em termos anglo-saxónicos, significa "profissão», ou se será o tipo ideal da profissão liberal, à moda francesa. O relatório integra a contribuição de Ana Isabel Ribeiro (2002) com um estudo para a sociologia da arquitetura em Portugal, no qual expõe a alteração da ideia de arquiteto ao longo da história, descrevendo a passagem do «arquiteto-arqueólogo», diluído na Sociedade dos Arquitetos Portugueses, até à ideia de 'arquitetoartista' que se prolonga pelos anos 20 e 30 do século XX - é nesta proximidade com a arte que se sedimenta uma maior consciência de grupo profissional. $\mathrm{O}$ corpo do trabalho dedica um ponto ao fator género em arquitetura, que tem um grande peso na explicação das diferenças de situação e atitudes entre os/as arquitetos/as. Os/as autores/as referem que

(...) embora o número de profissionais do sexo feminino tenha aumentado exponencialmente nas últimas duas décadas, esse aumento é dependente da abertura do sistema universitário e, portanto, do escalão etário, graças nomeadamente à abertura de cursos privados de arquitectura a partir de 1996 (Cabral e Borges, 2006: 38).

Em 2006, a percentagem de mulheres licenciadas em arquitetura era já superior a $50 \%$ mas a de arquitetas ativas era $35.5 \%$, clarificando o universo masculino que caracteriza a disciplina. No ano letivo 1988/89, ano letivo inaugural da licenciatura em arquitetura no Departamento de Arquitetura da Universidade de Coimbra (Darq), inscreveram-se 67 alunos, dos quais 23 eram mulheres. Em 2010/11, registou-se o mesmo número de inscrições mas o número de mulheres aumentou para 37. Todavia, no quadro geral do ensino superior de 2009, a percentagem de homens a estudar arquitetura era de $56 \%$, contra $44 \%$ de mulheres ${ }^{8}$. O corpo docente permanece maioritariamente masculino em quase todas as Faculdades e Departamentos de Arquitetura de Portugal - por exemplo, no Darq lecionam ao todo 39 docentes, dos quais apenas cinco são do sexo feminino.

Por um lado, o ritmo da feminização da disciplina tem sido mais lento que o de outras profissões liberais (como a advocacia e a medicina), fenómeno que se apresenta universal e que constitui o primeiro indício do encerramento sociocul-

8 Dados cedidos pelo GPEARI - Gabinete de Planeamento, Estratégia, Avaliação e Relações Internacionais (via e-mail, 25 Novembro 2011). 
tural da profissão - as arquitetas são genuínas solitárias no contexto português que acompanha o cenário internacional. Por outro lado, as arquitetas demonstram percursos e perfis profissionais diferentes dos seus colegas masculinos. Apesar de elas se distinguirem por frequentarem mais pós-graduações académicas e formações profissionais, apresentam menos atividade prática durante a licenciatura, exibindo um 'perfil mais escolástico' e menos prático. Estes fatores mostram-se relevantes para a obtenção e manutenção de um emprego de qualidade, pois

(...) os arquitectos predominam tipicamente entre aqueles que fazem arquitectura por conta própria e as arquitectas entre os que exercem a profissão como assalariados ou em regime de prestação de serviços (...) os vínculos laborais das mulheres são tipicamente mais precários do que os dos homens» (Cabral, 2006: 40).

Os resultados do estudo, que temos vindo a seguir (Cabral e Borges, 2006), mostram que os arquitetos em Portugal recebem salários claramente superiores aos das colegas, também devido ao fato destas trabalharem menos horas, acumularem menos formas de atividade e exercerem as funções menos qualificadas dentro da profissão. Na escolha da profissão, as mulheres dizem ser influenciadas pela família e pelas saídas profissionais em arquitetura, enquanto os homens são mais influenciados pelos amigos e pelo prestígio que atribuem à profissão. Estes detalhes são significativos pois o mainstream da profissão tende a configurar padrões e atitudes distintos: as mulheres são mais críticas em relação a esta, mais insatisfeitas com as condições em que a exercem e defendem uma evolução da arquitetura no sentido da regulamentação e da proteção ambiental, enquanto os homens se revelam menos exigentes com as condições em que exercem a profissão e continuam a defender a ideia de arquiteto-autor. Porém, quantas mais arquitetas estiverem envolvidas na profissão e mais influência exercerem sobre o ideal da arquitetura, mais as jovens serão encorajadas a juntarem-se à disciplina.

\section{b) (Ir)Reconhecimento das arquitetas e as suas experiências profissionais}

No ensaio Why Have There Been no great Women Artists?, Linda Nochlin (1994) debruça-se sobre o cenário global e exerce grande influência no questionamento da ausência das mulheres e do feminismo das artes e da arquitetura. A autora coloca a dominação masculina como uma das variadas «injustiças» que devem ser ultrapassadas na criação de uma verdadeira transparência social. Deste modo, devemos ver a «não-declarada» subjugação à subjetividade masculina como uma das distorções intelectuais onde decorrem os fatos históricos.

O desencorajamento e a (o)pressão a que as mulheres estão sujeitas é um problema que não pode ser visto através do ponto de vista dos grupos dominantes porque «(...) não consta nas nossas estrelas, nas nossas hormonas, nos nossos 
círculos menstruais, ou os nossos espaços internos vazios, mas nas nossas instituições e na nossa educação» ${ }^{9}$ (Nochlin, 1994: 150). A questão da igualdade e do reconhecimento desenvolve-se na natureza das estruturas institucionais e na visão da realidade que impõe. Por exemplo, entre 1979 e 2001, os prémios Pritzker foram entregues apenas a homens; em 2004, Zaha Hadid recebeu o mais prestigiado galardão em arquitetura, e em 2010, Kazuyo Sejima é a vencedora em parceria com o arquiteto Ryue Nishizawa. O prémio Pritzker começou agora a ser atribuído a mulheres arquitetas (e a arquitetos de países fora do mainstream arquitetónico), mas, em comparação, as mulheres receberam o Prémio Nobel em todas as áreas do conhecimento desde cedo (Marie Curie foi a primeira em 1903). Outro exemplo é o American Institute of Architects Golden Medal que foi apenas entregue a arquitetos do sexo masculino, de 1907 a 2011. Em 2000, nos EUA, as conceituadas revistas Architecture e Architectural Record apresentaram editoriais onde lamentavam a situação das arquitetas na profissão e pressionavam para o fim da sua exclusão na comunidade da arquitetura. Numa sociedade dominada pelos homens, denunciaram que há muitas formas subtis de perpetuar os preconceitos contra as mulheres, de fingir ser inocente de práticas discriminatórias e de evitar tomar a iniciativa de promover as mudanças. A dificuldade do tema prende-se exatamente com a subjetividade e com um estranho encobrimento das arquitetas. Annete Fischer, ex-Presidente do Royal Institute of British Architects, tem vindo a defender a causa das mulheres e das minorias na arquitetura com uma significativa contribuição para «quebrar o teto de vidro» suspenso sobre estes grupos. Assim, quanto mais pessoas estiverem envolvidas no mainstream da arquitetura como Fischer, cada vez menos aceitarão o estereótipo do arquiteto white male superstar.

Se considerarmos que a arquitetura é uma construção social, então podemos refletir sobre o que a ausência sintomática da mulher na profissão sugere sobre a cultura ocidental e os princípios que regulam a produção do espaço e da disciplina:

Tal como a ausência de qualquer dos sexos de um grande círculo eleitoral deve indicar alguma crise interna na qual o género desempenha um papel crucial, a ausência de mulheres na profissão aponta para uma crise profunda, relacionada com o género, na base da arquitetura ${ }^{10}$ (Hughes, 1996: xi).

Denise Scott-Brown nota a complacência de jovens mulheres que experienciaram um evidente sexismo durante o período de formação escolar ou no início

9 No original: «(...) lies not in our stars, our hormones, our menstrual circles, or our empty internal spaces, but in our institutions and our education».

10 No original: «Just as the absence of either sex from a large constituency must indicate some internal crisis in which gender plays a crucial role, the absence of women from the profession points to a profound gender-related crisis at the base of architecture». 
da prática profissional. Cita a sua própria experiência como arquiteta e companheira do arquiteto Robert Venturi:

Nos últimos vinte anos, eu não me lembro de um artigo importante de um crítico de alto gabarito sobre uma mulher arquiteta (...) Durante alguns anos, quem escreveu sobre arquitetura estava interessado no sexismo e no movimento feminista e queriam discuti-los comigo. Em entrevista conjunta, eles perguntariam ao Bob sobre o trabalho e questionar-me-iam sobre o meu 'problema de mulher'. 'Escreva sobre o meu trabalho!' Eu pedia, mas raramente o fizeram ${ }^{11}$ (Brown, 1989: 245).

Sobretudo durante o século $X X$, várias equipas de arquitetura eram formadas em parceria, muitas vezes entre marido e mulher, mas a inserção da mulher na profissão foi ocultada da história atrás do pano do «arquiteto-herói» e do constrangimento de ser «a mulher do arquiteto» - casos como Frank Lloyd Wright/Marion Mahony, Aino Marsio/Alvar Aalto, ou Mies van Der Rohe/Lilly Reich.

As conquistas sociais da suposta emancipação profissional da mulher surgem ainda como uma imagem distorcida: há uma grande dificuldade em relacionar o trabalho, que se pretende a tempo inteiro, com a maternidade. Consequentemente, muitas arquitetas optam por uma carreira académica, na tentativa de conseguir conciliar a vida privada com a profissional (que pode incluir, além da pedagogia, a investigação e o trabalho teórico). Todavia, Kullack refere que:

(...) as mulheres costumavam ter uma pequena ou nenhuma participação na criação das estruturas a que estão submetidas - particularmente no mundo académico. Como resultado, as mulheres geralmente encaixam-se com menor precisão nessas estruturas e são menos propensas a cumprir os padrões de qualidade por elas definidos, que servem para preservar e estabelecer o sistema; por conseguinte, as mulheres estão menos presentes nelas. Este fenómeno tem sido adequadamente descrito como «reprodução homossocial» - a tendência de o decisor escolher aqueles que são semelhantes a si mesmo muitas vezes impede as mulheres e os membros das minorias de entrar em posições que têm a autoridade para fazer as restrições que interessam $^{12}$ (Kullack, 2010: 8).

11 No original: «In the last twenty years, I cannot recall one major article by a high price critic about a woman architect (...) For a few years, writers on architecture were interested in sexism and the feminist movement and wanted to discuss them with me. In joint interview, they would ask Bob about work and question me about my 'woman's problem'. 'Write about my work!' I would plead, but they seldom did».

12 No original: «(...) women used to play little or no part in the creation of the structures, which they are subjected to - particularly within the academic world. As a result women usually fit less accurately into those structures, and are less likely to fulfill the quality standards defined by them, which serve to preserve and establish such system; therefore women are less present within them. This phenomenon has been adequately described as 'homo-social reproduction' 
Sobre as condições da profissão, Barbara Bestor nota a ausência da participação feminina nos grandes projetos de arquitetura, como os auditórios ou os museus, e comenta a importância da politização sobre este tema nas escolas, pois segundo a sua experiência pessoal:

Nós começámos um grupo Mulheres na Arquitetura, sobretudo porque grande parte dos nossos colegas eram homens, exceto um grupo que eram as amigas jovens do professor. Essa era uma mensagem deprimente para as estudantes. Nós também olhávamos em volta para os ateliers liderados por mulheres e claro que não eram muitos $^{13}$ (Bestor, 2010: 120).

As melhorias no local de trabalho são notórias e as alterações ao cenário global na arquitetura têm de ser reconhecidas - hoje há mais mulheres estudantes e professoras de arquitetura, como também aumentou o número de mulheres que lideram projetos e ateliers. Como notou Adele Santos (2005), reitora da MIT School of Architecture and Planning,

As empresas chefiadas por mulheres estão a crescer, e estão a obter projetos porque são consideradas mais interativas com os clientes. Mais e mais mulheres permanecem na profissão. Algumas formam-se, criam os seus filhos ou filhas, e entram mais tarde. Estou muito otimista sobre o importante papel que as mulheres vão ter na profissão $^{14}$ (Santos apud Wright 2005, s/p).

«Eu não posso, em plena consciência, recomendar a arquitetura como profissão para mulheres» ${ }^{15}$, comentava Belluschi em 1989 (Belluschi apud Berkeley, 1989: xvii). Até agora, as condições na profissão têm mudado paulatinamente; todavia, quando acompanhadas de tempos de crise económica (por vezes sucedidas de crises sociais e culturais), podem ser motivo de retrocessos em vários sentidos. Em Portugal, a arquitetura é uma das áreas qualificadas com níveis de desemprego mais elevados ${ }^{16}$, levando, por conseguinte, a taxas elevadíssimas de

- the tendency of the decision-maker to pick those who are similar to themselves often prevents women and minorities from getting into positions which have the authority for the relevant restricting».

13 No original: «We started a Women in Architecture group, mainly because almost all of our faculty were men, except a couple who were the much younger girlfriends of the male professor. It was a depressing message for the female students. We also looked around for female-led offices and of course there weren't many».

14 No original: «Firms headed by women are growing, and they are getting projects because of being considered more responsive to clients, more interactive. More and more women are staying in the profession. Some are graduating, raising their children, and entering later. I am very optimistic about the significant role women will be playing in the profession».

15 No original: «I cannot, in whole conscience, recommend architecture as a profession for girls».

16 Em 2014, a taxa de desemprego era de 19\%, a mais elevada da Europa, à frente da Espanha e da Grécia, ambas com 12\% (Architects'Council of Europe, 2015). 
emigração ${ }^{17}$ - facto que afeta tanto as mulheres como os homens. Mas também se sabe que é precisamente nestas fases que os grupos menos favorecidos mais sofrem - em termos de empregabilidade, de desigualdade de salários ou de usufruto de tempos livres - logo, a crise poderá provocar alterações significativas no estado da profissão nos próximos anos. Mais, a «carreira» como outrora conhecida poderá passar a ser um conceito demasiado instável - o estado da disciplina apenas permite que esta se concretize em alguns cargos públicos, em grandes empresas (de construção e/ou arquitetura) ou através do sobrelotado trabalho académico. As mulheres estão, sem dúvida, mais incluídas na disciplina, mas ainda existem dados preocupantes: o número de estudantes (mulheres) que iniciam os estudos, que os terminam e que exercem a profissão, em relação ao de colegas do sexo masculino, ainda se mantém muito díspar. A verdade é que conjugar as esferas profissional com a pessoal-familiar-social, transversal a qualquer profissão, ainda é um trabalho árduo para as mulheres, que se debatem com um mercado de trabalho instável e exigente e com a dedicação à família e à vida social. Eliana Santos faz uma incisiva análise sobre estes temas em «When it's bad it's murder» (2014), onde comenta que todos estes fatores estão agora conjugados com a meta da máxima produtividade (em todas as esferas supracitadas) consequentemente, surge o conflito no binómio trabalho-ócio, com os tempos livres a serem afetados. Desde cedo, os e as estudantes de arquitetura são motivados/as e obrigados/as a trabalhar em horários alargados e stressantes; portanto, quando transposto para a vida laboral, o excesso de trabalho começa a ser percebido como algo normal.

\section{Conclusão}

A arquitetura contemporânea em crise, também em Portugal, necessita ser entendida enquanto produção cultural e social atravessada por problemáticas, questões e conexões transversais à contemporaneidade em sentido alargado concetual, social, económico, político. Estes contextos manifestam-se no projeto de arquitetura, na sua linguagem ou na composição, nos métodos de desenho e produção, nos mecanismos de afirmação autoral e de organização profissional. $\mathrm{O}$ mundo da arquitetura não é neutro em relação às questões de igualdade de género e as mulheres continuam a ter de se esforçar muito mais para verem o tra-

Segundo declarações de João Santa-Rita, presidente da Ordem dos Arquitectos, ao jornal Construir: «em números redondos, são pedidos por mês na Ordem dos Arquitectos cerca de 50 certificados que permitem aos arquitectos se apresentarem em associações congéneres fora do país, um número que tem vindo a crescer desde 2009 e que estava em 240 pedidos por anos em 2008 e se encontra actualmente no dobro, um aumento de $50 \%$. Por outro lado, diminuíram os pedidos de inscrição na Ordem dos Arquitectos, uma redução que João Santa-Rita estima em 25\%» (Sevilha, 28 de outubro 2014). 
balho valorizado - havendo, portanto, ainda um longo caminho a percorrer. As ideias de arquitetura desenvolvem-se e transformam-se de acordo com os desafios que enfrentam ao longo dos tempos; um dos desafios que se impõe é a refutação da divisão de género na profissão e na educação, transformando a arquitetura numa estrutura de colaboração com iguais oportunidades, que tenha em conta o talento, o esforço e o trabalho.

Os ensaios de um vasto leque de autores e autoras revelaram, ao longo do tempo, tanto o género associado ao espaço e à arquitetura (e vice-versa), como as vozes esquecidas das arquitetas, traduzindo a tentativa de descobrir a ligação da mulher ao ambiente construído através da sua própria perspetiva e do desejo de se instituírem como sujeitos no sistema arquitetónico. A partir da história e da partilha de experiências pessoais, as arquitetas podem estabelecer as estruturas da sua resistência e da sua permanência na profissão, de tal forma que acabem por traçar uma outra face da história oficial. Por sua vez, a combinação da «voz pública» com a «voz íntima» constrói a história que nunca foi contada, rompendo a cadeia ideológica erigida pela História (dos homens). Quanto mais pessoal e diversificada for essa narrativa, mais ela se torna verdadeira e abrangente na medida em que engloba as mais variadas experiências vividas pelas arquitetas e pelas mulheres que usufruem da arquitetura.

\section{Referências bibliográficas}

Architects'Council of Europe (2015), The Architectural Profession in Europe 2014 - A Sector Study, [em linha] http://www.ace-cae.eu/fileadmin/New_Upload/7._Publications/ Sector_Study/2014/EN/2014_EN_FULL.pdf [consultado em 6 março 2016]

Bestor, Barbara et al. (2010), "On Success and Career and Conditions Therefore», in Tanja Kullack (org.), Architecture: A Woman's Profession, Berlin, Jovis, 120-127.

Brooks, Alison; Leon, Monica Ponce de et al. (2010), «On Autorship and Genius», in Tanja Kullack (org.), Architecture: A Woman's Profession, Berlin, Jovis, 20-25.

Brown, Denise Scott- (1989), «Room at the Top? Sexism and the Star System in Architecture», in Ellen Perry Berkeley (org.), Architecture: A Place for Women, Washington DC, Smithsonian Institution Press, 237-246.

Brown, Denise Scott- et al. (2010), «On Societal Changes and Challenges», in Tanja Kullack (org.), Architecture: A Woman's Profession, Berlin, Jovis, 112-113.

Cabral, Manuel Villaverde (coord.), Borges, Vera (2006), Relatório Profissão: Arquitecto/a, Lisboa, Universidade Lisboa - Instituto de Ciências Sociais Estudo e Ordem dos Arquitectos.

Heumann, Michael (1998), Machine + War - Woman = Futurism: Marinetti's Recreation of Creation, [em linha] http://thelibrary.hauntedink.com/ghostinthemachine/ch3.html [consultado em 2 fevereiro 2012].

Hughes, Francesca (org.) (1996), The Architect: Reconstructing her practice, Cambridge, The MIT Press.

Lang, Evelyne (1992), Les Premieres femmes architects de Suisse, tese de doutoramento, Departement d'Architecture, École Polytechnique Federale de Lausanne. 
Nochlin, Linda (1994), «Why Have There Been No Great Women Artists?», in Linda Nochlin, Women, Art, and Power, New York, Harper and Row, 145-178.

Sá, Flávia Carvalho de (2010), Profissão: Arquiteta: Formação profissional, mercado de trabalho e projecto arquitectónico na perspectiva das relações de género, Dissertação de mestrado em Arquitetura e Urbanismo, Faculdade de Arquitetura e Urbanismo da Universidade de São Paulo.

Saint, Andrew (1983), The Image of the Architect, UK, Yale University Press.

Sevilha, Ana Rita (28 de outubro 2014), «Pedidos à Ordem dos Arquitectos para sair do país aumentaram em 50\%». Construir [em linha] http://www.construir.pt/2014/10/28/ pedidos-a-ordem-dos-arquitectos-para-sair-do-pais-aumentaram-em-50/. Consultado em 6 março 2016.

Sousa Santos, Eliana (2014), «When it's bad it's murder: Architecture's working environment, [em linha] https://www.academia.edu/17354036/When_it_s_bad_it_s_murder_Architecture_s_Working_Environment_Cuando_es_malo_es_asesinato_El_Amb iente_de_Trabajo_en_Arquitectura [consultado em 12 novembro 2015].

Toy, Maggie (2001), The Architect: Women in contemporary architecture, London, Wiley Academy.

Tzonis, Alexander (1976), «Para um ambiente não-opressivo», in José Manuel Rodrigues (org.), Teoria e Crítica de Arquitectura - Século XX, Lisboa, Ordem dos Arquitectos Seccção Regional do Sul e Caleidoscópio, Outubro 2010, 649.

Wajcman, Judy (2001), «The Built Environment: Women's Place, Gendered Place», in Mary Wyer (org.), Women, Science and Technology: A Reader in Feminist Science Studies, New York, Routledge, 194-208.

Wright, Sarah H. (2005), «Santos' talk gives history of women in architecture», MIT Tech Talk, volume 49, número 19, 7 [em linha] http://news.mit.edu//2005/techtalk4919.pdf [consultado 25 Maio 2012]

Zabalbeascoa, Anatxu (2008), "Camino hacia la extrema sencillez», Jornal El País (16 novembro 2008). [em linha] http://elpais.com/diario/2008/11/16/eps/1226820412_ 850215.html [consultado em 17 de dezembro, 2011].

Lia Pereira Saraiva Gil Antunes. Arquiteta, Mestre pela Universidade de Coimbra em Julho de 2012, com a dissertação «Arquitetura: Substantivo Feminino: Contribuição para uma história das mulheres na arquitetura». Trabalha atualmente no escritório Formas Efémeras na área da arquitetura, museografia e arte urbana. liapantunes@gmail.com

Endereço: Formas Efémeras, Rua de Pedrouços, 37-4.ํㅡ, 1400-285 Lisboa

Artigo recebido em 11 de novembro de 2015 e aceite para publicação em 12 de abril de 2016. 